\title{
Biodyzelino, gauto naudojant sėjamųjų judrų aliejų, būvio ciklo rodikliai ir biologinis suirimas
}

\author{
Violeta Makarevičienė, \\ Eglè Sendžikienè \\ Aleksandro Stulginskio universitetas, \\ Fundamentiniu mokslu studiju institutas, \\ Chemijos katedra, \\ Studentu g. 11, \\ LT-53361 Akademija, Kauno r. \\ El.paštas: agrotech@asu.lt
}

Siekiant sumažinti neigiamą biodyzelino gamybos poveiki maisto sektoriui, būtina biodyzelino gamybai naudoti alternatyvias aliejingąsias / riebalingąsias žaliavas ar / ir atliekas. Biodyzelinui keliamus reikalavimus atitinka metilesteriai, gauti iš sẻjamųjų judrų aliejaus ir atliekinių riebalų mišinių santykiu $1: 1 . \mathrm{Nu}-$ statyta, kad būvio ciklo energijos veiksmingumo rodiklis $\left(\mathrm{R}_{1}\right)$ tiesiogiai priklauso nuo judrų derlingumo. Energijos kiekis, sunaudotas judrų aliejaus riebalų rūgščiu metilesterių (JME) gamybai, yra didesnis už iš JME išgaunamą energijos kieki (energijos veiksmingumo rodiklis mažesnis kaip 1), todèl esant $1,6 \mathrm{t} \mathrm{ha}^{-1}$ ir mažesniam judrų derliui, JME negalima priskirti atsinaujinantiems degalams. Riebalų rūgščių metilesteriai, gauti iš riebalingujų atliekų, pasižymi didesnèmis energijos veiksmingumo rodiklio vertèmis, palyginti su JME. Atliekinių riebalų rūgščiu metilesterių (AME) būvio ciklo energijos veiksmingumo rodiklis $R_{1}$ yra 4,94, o dvikomponenčių (JME-AME santykiu $1: 1$ ) degalų, kai judrų derlius $1,28 \mathrm{tha}^{-1}, \mathrm{R}_{1}-1,34$, o kai derlius $1,6 \mathrm{t} \mathrm{ha}{ }^{-1}, \mathrm{R}_{1}-1,5$. Nustatyta, kad judrų aliejaus ir atliekinių riebalų rūgščių metilesterių mišiniai (santykiu $1: 1$ ) atitinka biodegalams keliamus biologinio suirimo reikalavimus, nes per 21 parą biologiškai suyra daugiau nei $90 \%$ šių degalų.

Raktažodžiai: riebalų rūgščiu metilesteriai, gyvavimo ciklas, energijos veiksmingumo rodikliai, biologinis suirimas

\section{IVADAS}

Biodegalai dyzeliniams varikliams visoje Europos Sąjungoje daugiausiai gaminami iš rapsų aliejaus. Intensyviai plečiantis biodyzelino gamybai, nuolatos didejja rapsų gamybos žaliavos - sèklų poreikis. Rapsų aliejus yra naudojamas maistui, o dali jo nukreipiant biodegalų gamybai dideja aliejaus kaina, kyla nepasitenkinimas visuomenejje, ima trūkti žaliavos tiek maisto, tiek techninėms reikmèms. Pastaruoju metu rapsų auginimo plotų plètra dèl sejjomainos ir žemès tinkamumo rapsų auginimui yra ribota.

Siekiant sumažinti neigiamą biodyzelino gamybos poveiki maisto sektoriui, būtina biodyzelino gamybai naudoti alternatyvias aliejingąsias / riebalingąsias žaliavas ar / ir atliekas (Schwab et al., 1987; Tashtoush et al., 2004). Vienas iš tokių aliejingujų augalų - sejjamosios judros (Camelina sativa L.) (Vollmann et al., 2007). Dèl riebalų rūgščių sudèties (didelis polinesočiụjų rūgščių kiekis) (Abramovič et al., 2005; Peiretti, Meineri, 2007; Berti et al., 2011), judrų aliejaus riebalų rūgščių metilesteriai (JME) neatitinka apibrěžiančio biodyzelino kokybę standarto LST EN 14214 reikalavimų. Nustatyta, kad biodyzelinui keliamus reikalavimus atitinka metilesterių, gautų iš judrų aliejaus ir atliekinių riebalų, mišiniai santykiu 1: 1 (Zaleckas et al., 2012). Lietuvoje susidaro gyvūninès kilmès sunkiai utilizuojamų atliekų, kurios ribotai panaudojamos. Gyvūninès kilmès atliekos perdirbamos įmonèje UAB "Rietavo veterinarinè sanitarija“ gaminant lydytus techninius riebalus, kuriuos galima būtų panaudoti biodyzelino gamybai.

Diegiant naujų rūšių biodegalų gamybą ir naudojimą, būtina ịvertinti jų aplinkosauginius rodiklius 
bei palyginti su atitinkamais iprastinio biodyzelino rodikliais. Biodegalais laikomi tokie degalai, kurių ne mažiau kaip $90 \%$ suyra per 21 parą ir jų būvio ciklo energijos veiksmingumo rodiklis $\mathrm{R}_{1}$ didesnis nei 1 (Biodiesel producers association, 1998), mineralinio dyzelino $\mathrm{R}_{1}-0,885$. Dažniausiai naudojamo (kaip biodegalų) rapsų aliejaus riebalų rūgščių metilesterio (RME) energijos veiksmingumo rodiklis nustatytas daugelio šalių mokslininkų (Boo, 2003). Tirti ir kitų metilesterių, pagamintų iš ịvairių aliejingųjų sèklų aliejaus (saulègrąžų, jatrofų), energijos veiksmingumo rodikliai (Sheikh Davoodi et al., 2009; Kaewcharoensombat et al., 2011). Labiausiai energijos veiksmingumo rodiklių vertès svyruoja priklausomai nuo klimatinių sąlygų, ypač nuo derlingumo, gamybos technologijų. Tiriant biologinị rapsų aliejaus riebalų rūgščių metilesterių suirimą, nustatyta, kad 99,6 \% suyra per 21 parą. O mišinys, kuriame buvo $20 \%$ biodegalų, suyra du kartus greičiau negu grynas dyzelinas (Tyson et al., 2001; Atadashi et al., 2010).

Tačiau duomenų apie dvikomponenčių degalų energijos veiksmingumo rodiklius ar jų biologini suirimą nepavyko rasti.

Šio darbo tikslas - ịvertinti sejjamųjų judrų aliejaus ir gyvūninès kilmès riebalų rūgščių metilesterių būvio ciklo energijos veiksmingumo rodiklị, biologini suirimą ir palyginti su atitinkamais iprastinio biodyzelino (rapsų aliejaus metilesterių) rodikliais.

\section{METODAI IR SALYGOS}

Energijos sąnaudos žemès ūkyje $1 \mathrm{t}$ riebalų rūgščiu metilesteriams (RRME) pagaminti nustatytos vertinant tiesiogines (energija, gauta iš iškastinių šaltinių) ir netiesiogines (įdaiktintas) energijos sąnaudas. Idaiktintos energijos sąnaudos žemès ūkio mašinoms pagaminti, degalu sąnaudos nustatytos pagal Lietuvos agrarinès ekonomikos instituto pateiktus duomenis (Mechanizuotų žemès ūkio paslaugų ịkainiai, 2012). Judroms išauginti naudojamų trąšų ir augalų apsaugos priemonių įdaiktintos energijos sąnaudos nustatytos pagal rekomenduojamas tręšimo normas (Karčauskienè et al., 2012) bei naudojamų cheminių medžiagų energetinius ekvivalentus (Lal, 2004; Sheikh Davoodi et al., 2009). Vasarinèms judroms užauginti išberta $\mathrm{N}_{90} \mathrm{P}_{60} \mathrm{~K}_{60}$, gautas derlius siekè 1,28-1,29 $\mathrm{t} \mathrm{ha}^{-1}$. Žieminems judroms naudota trąšu $\mathrm{N}_{100} \mathrm{P}_{60} \mathrm{~K}_{60}$, derlius - 1,6 tha he (Referentil..., 1999; Karčauskienė et al., 2012).

Sejjamujjų judrų sẻklų ir gyvūninių riebalų perdirbimo ị biodyzeliną energijos sąnaudos ịvertintos pagal gamybos įrangos, ịdiegtos UAB „Rapsoila“, specifikaciją. Gamybos pajègumai - $10000 \mathrm{t} / \mathrm{metus}^{-1}$.

Būvio ciklo energijos veiksmingumo $\left(\mathrm{R}_{1}\right)$ rodiklis nustatytas pagal formulę:

$$
R_{1}=\frac{E_{B}}{E_{\check{z} . \bar{u}}+E_{g}}
$$

čia: $E_{B}$ - energija, išgaunama iš biodegalų, $\mathrm{MJ} \mathrm{t}^{-1}$

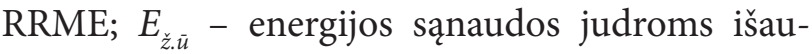
ginti ir paruošti aliejaus spaudimui, $\mathrm{MJ} \mathrm{t}^{-1} \mathrm{RRME}$; $E_{g}$ - energijos sąnaudos judrų aliejui spausti ir riebalinèms žaliavoms esterinti bei peresterinti, MJ t ${ }^{-1}$ RRME.

Biodegalų šilumingumas nustatytas kalorimetru IKA C2000 Basic pagal standarto DIN 51900 reikalavimus (DIN 51900). Degalų ir jų mišinių biologinis suirimas tirtas laikantis CEC L33-T-82 degalu biologinio suirimo vandenyje nustatymų. Tiriami degalai buvo ištirpinami anglies tetrachloride $\left(150 \mathrm{~g} \mathrm{l}^{-1}\right)$, $\mathfrak{t}$ méginius pridedama bakterinès kultūros ir inkubuojama nustatytą laiką. Kaip bakterinè kultūra imtas eliuentas po pirmosios nuotèų įrenginių valymo (mechaninio) stadijos iš UAB „Kauno vandenys“. Jame buvo ne mažiau kaip $10^{6} \mathrm{CFU}^{0} \mathrm{ml}^{-1}$ (CFU - koloniją matuojantis vienetas) bakterijų, kurių kiekis tirtas Dip Slide testu. Pasibaigus inkubavimo laikui, biodegalų mèginiai ekstrahuoti anglies teprachlorinu ir likutinis nesuirusių degalų kiekis nustatytas infraraudonosios spektroskopijos metodu, prietaisu FT-IR spektrometru Spectrum GX (Perkin Elmer).

\section{TYRIMŲ REZULTATAI IR JŲ APTARIMAS}

Nustatant riebalų rūgščių metilesterių (RRME) būvio ciklo energijos veiksmingumo rodiklį $R_{1}$ buvo ivvertintos energijos sąnaudos žaliavoms užauginti, jas paruošti perdirbimui ir perdirbti ị biodyzeliną. Pateiktos bendrosios energijos sąnaudos, reikalingos $1 \mathrm{t}$ judrų aliejaus riebalų rūgščių metilesterių (JME) pagaminti (1 lentelè). Lietuvoje judros pramoniniu būdu dar neauginamos, pradiniai judrų 
1 lentelè. Bendrosios energijos sąnaudos pagaminti $1 \mathrm{t} \mathrm{JME}$

Table 1. Total energy consumption for $1 t$ JME production

\begin{tabular}{|c|c|c|c|c|}
\hline \multirow[t]{2}{*}{ Energijos poreikis / Energy demand } & \multicolumn{4}{|c|}{$\begin{array}{c}\text { Bendrosios energijos sąnaudos } \mathrm{MJ} \mathrm{t}^{-1} \mathrm{JME} \text { esant } \\
\text { skirtingam judrų derlingumui } \\
\text { Energy consumption } \mathrm{MJ}^{-1} \mathrm{JME} \text { of Camelina } \\
\text { sativa productivity }\end{array}$} \\
\hline & $1,28 \mathrm{t} \mathrm{ha}^{-1}$ & $\%$ & $1,6 \mathrm{t} \mathrm{ha}^{-1}$ & $\%$ \\
\hline \multicolumn{5}{|l|}{ Žemès ūkis / Agriculture } \\
\hline $\begin{array}{l}\text { ìdaiktinta energija ž. ū. mašinose ir irrenginiuose } \\
\text { agromachinery and equipment }\end{array}$ & 5173,6 & 10,9 & 4139,9 & 10,2 \\
\hline degalai ir tepalai / fuel and oils & 9704,2 & 20,5 & 7763,3 & 19,1 \\
\hline $\begin{array}{l}\text { iddaiktinta energija sèklose ir cheminèse medžiagose } \\
\text { seeds and chemicals }\end{array}$ & 18146 & 38,3 & 14453 & 35,5 \\
\hline Iš viso / Total & 33023,8 & 69,7 & 26356,2 & 64,8 \\
\hline \multicolumn{5}{|l|}{ Spaudimo padalinys / Oil pressing } \\
\hline elektros energija / electricity & 4117,7 & 8,7 & 4117,7 & 10,1 \\
\hline įdaiktinta energija įrangoje / equipment & 2289 & 4,8 & 2289 & 5,6 \\
\hline Iš viso / Total & 6406,7 & 13,5 & 6406,7 & 15,7 \\
\hline \multicolumn{5}{|l|}{ Peresterinimo padalinys / Transesterification } \\
\hline elektros energija / electricity & 2745,2 & 5,8 & 2745,20 & 6,7 \\
\hline idaiktinta energija irangoje / equipment & 1807,8 & 3,8 & 1807,80 & 4,4 \\
\hline idaiktinta energija cheminèse medžiagose / chemicals & 3390,1 & 7,2 & 3390,10 & 8,4 \\
\hline Iš viso / Total & 7943,1 & 16,8 & 7943,10 & 19,5 \\
\hline Iš viso / Grand Total & 47373,6 & 100 & 40706 & 100 \\
\hline
\end{tabular}

auginimo tyrimai atlikti LAMMC Vėžaičiu filiale. Šių tyrimų rezultatai atskleidè, kad sėjamųjų vasarinių judrų vidutinis derlingumas $1,28 \mathrm{t} \mathrm{ha}^{-1}$, o žieminių - 1,60 $\mathrm{t} \mathrm{ha}^{-1}$.

Reikiamas kiekis judrų sèklų $1 \mathrm{t} \mathrm{JME} \mathrm{pagaminti}$ buvo nustatytas pagal aliejaus kieki judrų sèklose (39 \%) ir riebalų rūgščių metilesterių išeigą, gaunamą taikant UAB „Rapsoila“ instaliuotą ìrangą. Paaiškejo, kad $1 \mathrm{t} \mathrm{JME} \mathrm{pagaminti} \mathrm{reikia} \mathrm{2,9} \mathrm{t} \mathrm{judru}$ sèklų.

Iš pateiktų duomenų aišku, kad žemès ūkiui tenka didžiausia energijos sąnaudų dalis $(64,8-$ $69,7 \%$ ), palyginti su energijos sąnaudomis, tenkančiomis aliejaus spaudimui ir peresterinimui (1 lentelè). Didžiausią energijos sąnaudų dalị (35,5-38,3 \%) nuo bendrų sąnaudų sudaro energija, ịdaiktinta trąšose ir cheminèse medžiagose, naudojamose žemès ūkyje. Peresterinimo stadijoje energija, i̇daiktinta cheminèse medžiagose, siekia 7,2-8,4\%.

Bendrosios energijos sąnaudos JME gamybai yra atvirkščiai proporcingos sẻjamųjų judrų derlingumui. Esant $1,28 \mathrm{t} \mathrm{ha}^{-1}$ judru derlingumui, bendros energijos sąnaudos yra $47373,6 \mathrm{MJ} \mathrm{t}^{-1}$ JME, kai derlingumas 1,6 t ha ${ }^{-1}-40706 \mathrm{MJ} / \mathrm{t}$ JME. Esant mažesniam derlingumui, energijos są- naudos $1 \mathrm{t}$ JME pagaminti padideja $14 \%$. Tai lemia didesnès energijos sąnaudos žemès ūkyje tam pačiam judrų sẻklų kiekiui išauginti.

Remiantis ankstesnių tyrimų rezultatais (Zaleckas et al., 2012) buvo nustatyta, kad grynų JME negalima naudoti degalams dyzeliniuose varikliuose, nes neatitinka standarto LST EN 14214 reikalavimų. Minèto standarto reikalavimus atitinka judrų aliejaus ir gyvūninių riebalų metilesterių mišiniai santykiu $1: 1$.

Atsižvelgiant ị tai, kad gyvūninès kilmès riebalai yra atliekiniai, jų panaudojimas problematiškas, energijos sąnaudos jų gamybai nebuvo skaičiuotos. Tačiau sudetingesnis ir energetiškai imlesnis biodyzelino iš atliekinių riebalų gamybos procesas. $1 \mathrm{t}$ atliekinių gyvūninių riebalų rūgščių metilesterių gaunama iš $1075 \mathrm{~kg}$ atliekinių riebalų, kuriuose vidutiniškai yra 2,6 \% drègmès. Riebalinių atlieku rūgštingumas yra didesnis kaip $2 \%$, todèl prieš tradicinị šarminị peresterinimą būtina esterinti laisvąsias riebalų rūgštis, t. y. gamybos procesas papildomas dar viena esterinimo (naudojant rūgščius katalizatorius) stadija. 1 pav. pateiktos energijos sąnaudos, tenkančios $1 \mathrm{t}$ gyvūninès kilmès metilesterių ir riebalinių atliekų gamybai. Atliekinių riebalų peresterinimas yra tapatus judrų aliejaus 


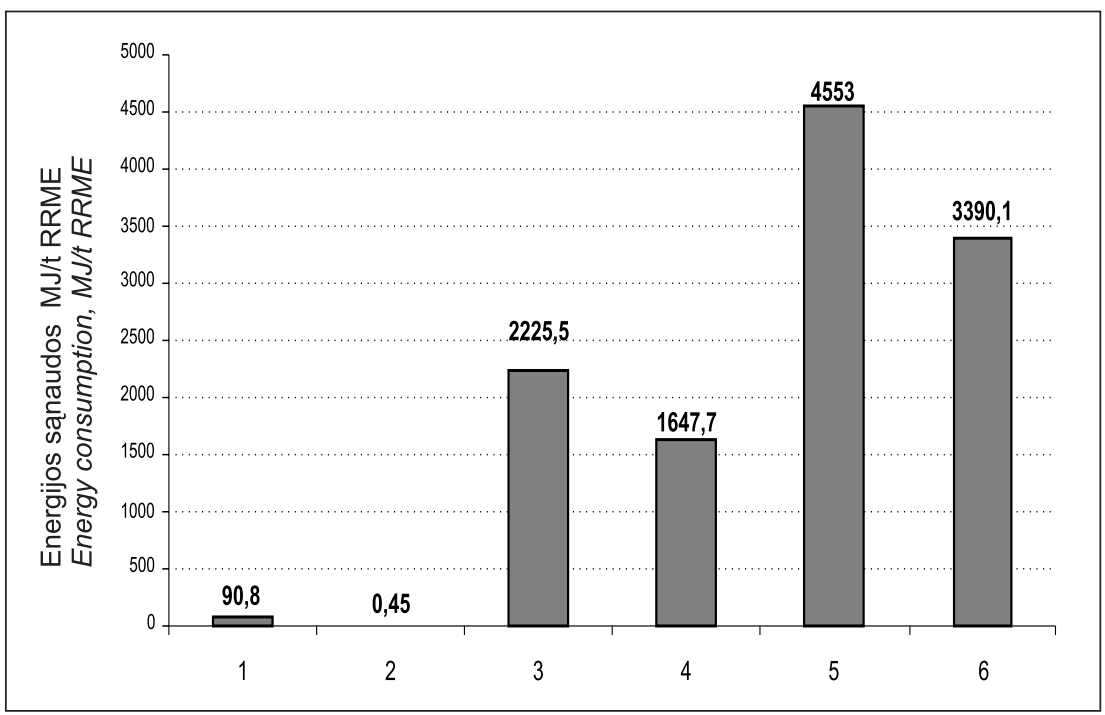

1 pav. Atliekinių riebalų $1 \mathrm{t}$ metilesterių gamybos energijos sąnaudos: 1 - džiovinimas, 2 - filtravimas, 3 - esterinimo padalinys (elektros energija, įranga), 4 - esterinimo padalinys (cheminèse medžiagose), 5 - peresterinimo padalinys (elektros energija, įranga), 6 - perseterinimo padalinys (cheminèse medžiagose)

Fig. 1. Total energy consumption for 1 t animal waste methyl esters production: 1 - Drying, 2 - Filtering, 3 - Esterification (electricity, equipment), 4 -Esterification (chemicals), 5 - Transesterification (electricity, equipment), 6 - Transesterification (chemicals)

peresterinimui, todèl peresterinimo sąnaudos imtos tokios pat, kaip ir judrų aliejaus riebalų rūgščių metilesterių (JME) gamybai.

Atliekinių riebalų metilesterių (AME) gamyboje didžiąją bendrụjų energijos sąnaudų dali, net $42,3 \%$, sudaro esterinimui ir peresterinimui naudojamose cheminèse medžiagose iddaiktinta energija. Atliekinių riebalų paruošimo esterinimui ir peresterinimui operacijos reikalauja palyginti mažai iškastinès energijos $(0,76 \%$ bendrųų energijos sąnau$\mathrm{dų})$. Nors papildoma atliekinių riebalų esterinimo operacija reikalauja $3873,2 \mathrm{MJ} \mathrm{t}^{-1}$ energijos (32,8 \% bendrųjų sąnaudų), tačiau bendrosios energijos sąnaudos (gaminant AME) yra 5,2-6 mažesnès, palyginti su JME gamyba. $1 \mathrm{t}$ AME pagaminti reikalinga 8 034,03 MJ bendrosios energijos sąnaudų.

Ivertintos energijos sąnaudos $1 \mathrm{t}$ optimalios sudèties mišinio JME-AME gamybai, kuri priklauso nuo judrų derlingumo (2 lentelè).

Vertinant bendrąsias energijos sąnaudas dvikomponenčių degalų JME-AME (1:1) gamyboje nustatyta, kad žemès ūkiui tenka daugiau kaip 50 \% visų energijos sąnaudų, todèl judrų derlingumas yra vienas svarbiausių faktorių, darančių ịta- ką bendrosioms energijos sąnaudoms biodyzelino būvio cikle. Kai judrų derlingumas yra 1,28 $\mathrm{t} \mathrm{ha}^{-1}$, sąnaudos žemès ūkyje - $16511,9 \mathrm{MJ} \mathrm{t}^{-1}$, o esant 1,6 $\mathrm{t} \mathrm{ha}^{-1}$ derlingumui, energijos sąnaudos žemès ūkyje yra $20 \%$ mažesnès ir siekia $13178,1 \mathrm{MJ} \mathrm{t}^{-1}$.

Norint nustatyti gyvavimo ciklo energijos veiksmingumo rodiklį, ịvertintos riebalų rūgščiu metilesteriuose ir jų mišiniuose sukauptos energijos vertès (šilumingumas), kurios buvo:

JME-AME (1:1) mišinio - 39,68 $\mathrm{MJ} \mathrm{kg}^{-1}$;

$\mathrm{AME}-39,7 \mathrm{MJ} \mathrm{kg}^{-1}$;

JME - 38,79 $\mathrm{MJ} \mathrm{kg}^{-1}$.

Nustatytos riebalų rūgščiu metilesterių būvio ciklo energijos veiksmingumo rodiklio vertès AME $\mathrm{R}_{1}-4,94$, JME $\mathrm{R}_{1}-0,82$ (kai derlingumas $1,28 \mathrm{t} / \mathrm{ha}$ ) ir 0,95 (kai derlingumas $1,6 \mathrm{t} / \mathrm{ha}$ ). Energijos kiekis, sunaudotas JME gamybai, yra didesnis už iš JME gaunamą energijos kieki (energijos veiksmingumo rodiklis mažesnis kaip 1), todèl grynieji judrų aliejaus riebalų rūgščių metilesteriai negali būti priskiriami atsinaujinantiems degalams.

Ivertintas ir dvikomponenčių (JME-AME) degalų, atitinkančių standarto LST EN 14214 
2 lentelè. Bendrosios energijos sąnaudos $1 \mathrm{t}$ JME-AME $(1: 1)$ gamybai

Table 2. Total energy consumption for $1 \mathrm{t} J M E-A M E(1: 1)$ production

\begin{tabular}{|c|c|c|c|c|}
\hline \multirow[t]{2}{*}{ Energijos poreikis / Energy demand } & \multicolumn{4}{|c|}{$\begin{array}{c}\text { Energijos sąnaudos } \mathrm{MJ} \mathrm{t}^{-1} \mathrm{JME}-\mathrm{AME}(1: 1) \text {, kai judru } \\
\text { derlingumas } \mathrm{tha}^{-1} \text { ir } \% \\
\text { Energy consumption } M J t^{-1} \mathrm{JME}-\mathrm{AME}(1: 1) \text { of Camelina } \\
\text { sativa productivity }\end{array}$} \\
\hline & $1,28 \mathrm{t} \mathrm{ha}^{-1}$ & $\%$ & $1,6 \mathrm{t} \mathrm{ha}^{-1}$ & $\%$ \\
\hline $\begin{array}{l}\text { Žemės ūkis (judrų auginimas) } \\
\text { Agriculture (Camelina sativa growing) }\end{array}$ & 16511,9 & 55,7 & 13178,1 & 50,09 \\
\hline Sëklu spaudimo padalinys / Seed pressing & 3203,35 & 10,8 & 3203,35 & 12,18 \\
\hline $\begin{array}{l}\text { Riebalų ruošimo padalinys } \\
\text { Animal fat waste preparation }\end{array}$ & 45,6 & 0,2 & 45,6 & 0,17 \\
\hline Esterinimo padalinys / Esterification & 1936,6 & 6,5 & 1936,6 & 7,36 \\
\hline Peresterinimo padalinys / Transesterification & 7943,1 & 26,8 & 7943,1 & 30,2 \\
\hline Iš viso / Total & 29640,55 & 100 & 26306,75 & 100 \\
\hline
\end{tabular}

reikalavimus, būvio ciklo energijos veiksmingumo rodiklis (esant judrų derlingumui $1,28 \mathrm{t} \mathrm{ha}^{-1}$ ). Jis siekè 1,34 , o esant derlingumui $1,6 \mathrm{t} \mathrm{ha}^{-1}$, šio rodiklio vertè buvo 1,5 .

Vadinasi, dvikomponenčiai degalai, ì kurių sudetį įeina judrų aliejaus ir atliekinių riebalų metilesteriai santykiu $1: 1$, atitinka biodegalams keliamus reikalavimus: iš jų išgaunama daugiau energijos nei sunaudojama juos pagaminti.

Svarbus biodegalų aplinkosauginis rodiklis - ju biologinis suirimas gamtineje aplinkoje. Palyginamieji JME, AME ir JME-AME (1:1) biologinio suirimo tyrimų duomenys pateikiami 2 pav.

Iš gautų duomenų matyti, kad per 21 parą suiro $92,5 \% \mathrm{AME}, 98,3 \% \mathrm{JME}$ ir 96,3 \% JME-AME
(1:1). Paveiksle pavaizduota degalų biologinio suirimo dinamika rodo, kad atliekinių riebalų rūgščių metilesteriai (AME) pirmas 6 paras iro labai sparčiai, vèliau procesas sulètẻjo, o grynųjų judrų riebalų rūgščių metilesterių (JME) irimas iki 15 paros buvo tolygus ir tik vèliau sulètėjo. Biodegalams gali būti priskirti visi tirti riebalų rūgščių metilesteriai, nes jų biologinis suirimas per 21 parą siekè daugiau nei $90 \%$ ir buvo apie 1,5 karto greitesnis nei mineralinio dyzelino (D).

\section{IŠVADOS}

1. Būvio ciklo energijos veiksmingumo rodiklis $\left(\mathrm{R}_{1}\right)$ tiesiogiai priklauso nuo judrų derlingumo.

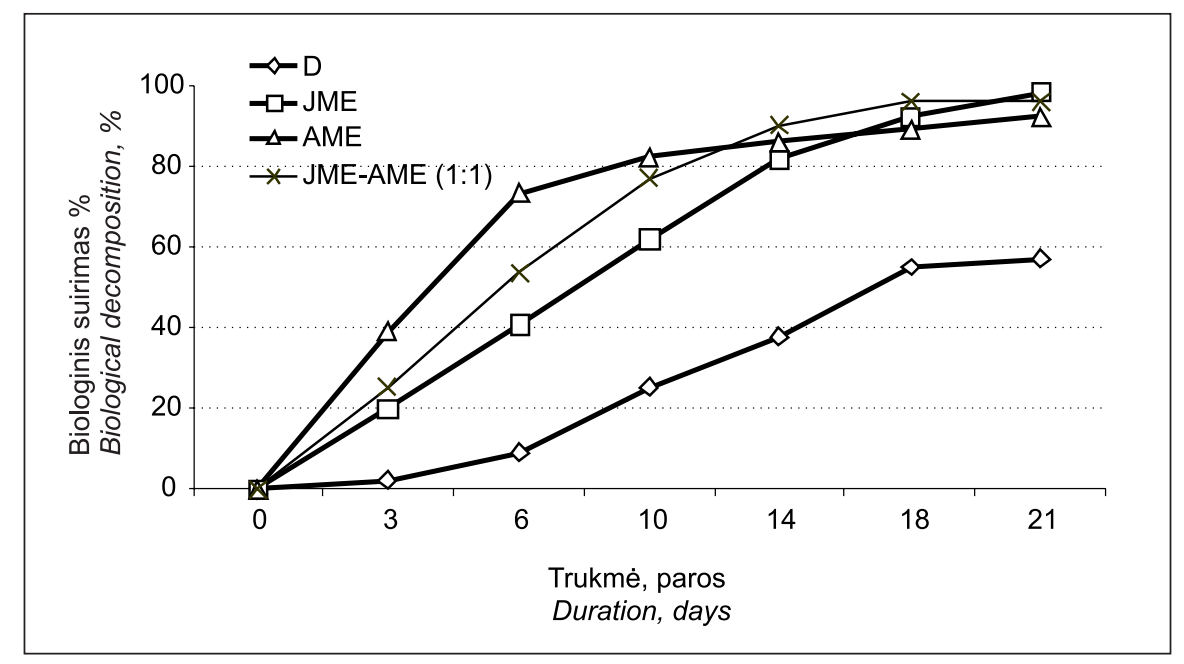

2 pav. Degalų biologinio suirimo dinamika

Fig. 2. Dynamics of fuel biological decomposition 
Energijos kiekis, sunaudotas judrų aliejaus riebalų rūgščių metilesterių (JME) gamybai, yra didesnis už iš JME išgaunamą energijos kiekị (energijos veiksmingumo rodiklis mažesnis kaip 1), todèl esant 1,6 t ha ${ }^{-1}$ ir mažesniam judrų derliui JME negalima priskirti atsinaujinantiems degalams.

2. Riebalų rūgščių metilesteriai, gauti iš riebalingụjų atliekų, pasižymi didesnèmis energijos veiksmingumo rodiklio vertèmis, palyginti su JME. Atliekinių riebalų rūgščių metilesterių (AME) būvio ciklo energijos veiksmingumo rodiklis $R_{1}-4,94$.

3. Dvikomponenčių (JME-AME santykiu $1: 1$ ) degalų būvio ciklo energijos veiksmingumo rodiklis, esant judrų derlingumui $1,28 \mathrm{t} \mathrm{ha}^{-1}$, siekia - 1,34. Kai derlingumas $1,6 \mathrm{t} \mathrm{ha}^{-1}$, šio rodiklio vertè yra 1,5 . Vadinasi, šie degalai atitinka biodegalams keliamus reikalavimus.

4. Judrų aliejaus ir atliekinių riebalų rūgščių metilesterių mišiniai (santykiu $1: 1$ ) atitinka biodegalams keliamus biologinio suirimo reikalavimus: per 21 parą biologiškai suiro daugiau nei $90 \%$ šių degalų, o jų suirimo greitis yra apie 1,5 karto didesnis nei mineralinio dyzelino.

Padėka. Tyrimą finansuoja Europos socialinio fondo agentūra ir Lietuvos Valstybè (Nr. VP13.1. - ŠMM-06-V-01-003). Autoriai dèkingi už pagalbą.

Gauta 20120605 Priimta 20121108

\section{LITERATŪRA}

1. Abramovič H., Abram V. 2005. Physico-chemical properties, composition and oxidative stability of Camelina sativa oil. Food Technology and Biotechnology. Vol. 43. No. 1. P. 63-70.

2. Atadashi I. M., Aroua M. K., Abdul Aziz A. 2010. High quality biodiesel and its diesel engine application: A review. Renewable and Sustainable Energy Reviews. Vol. 14. No. 7. P. 1999-2008.

3. Berti M., Wilckens R., Fischer S., Solis A., Johnson B. 2011. Seeding date influence on camelina seed yield, yield components, and oil content in Chile. Industrial Crops and Products. Vol. 34. P. 1358-1365.

4. Boo W. 1993. Environmental and energy aspects of liquid biofuels. Zentrum vor energiebesparing and schone technologie. No. 2. 148 p.
5. DIN 51900: 2005. Prüfung fester und flüssiger Brennstoffe - Bestimmung des Brennwertes mit dem Bomben-Kalorimeter und Berechnung des Heizwertes.

6. Industrial Use of Rape for Biodiesel in Czech Republic. 1998. Praha: Biodiesel Producers Association.

7. Karčauskienė D., Repšienè R., Zaleckas E. ir kt. 2012. Sejamosios judros - žaliava biodyzelino gamybai. AB Kopa. 42 p.

8. Lal R. 2004. Carbon emission from farm operations. Environment International. Vol. 30. P. 981990.

9. LST EN 14214. Automobiliniai degalai. Riebaly rūgščiu metilesteriai (RRME) dyzeliniams varikliams. Reikalavimai ir tyrimo metodai. Vilnius: Lietuvos standartizacijos departamentas, 2010.

10. LST EN 14918.

11. Mechanizuotǔ žemés ükio paslaugu ỉkainiai. 2012. I dalis. Pagrindinio žemès dirbimo darbai. II dalis. Pasèlių priežiūra ir šienapjūtès darbai. III dalis. Derliaus nuemimo darbai. Vilnius: Lietuvos agrarinès ekonomikos institutas.

12. Peiretti P. G., Meineri G. 2007. Fatty acids, chemical composition and organic matter digestibility of seeds and vegetative parts of false flax (Camelina sativa L.) after different lengths of growth. Animal Feed Science and Technology. Vol. 133. P. 341-350.

13. Referentil pour le calcul des bilans energetiques. 1999. Fichier Brochurb. 52 p.

14. Schwab A. W., Bagby M. O., Freedmann B. 1987. Preparation and properties of diesel fuel from vegetable oils. Fuel. Vol. 66. P. 1372-1378.

15. Sheikh Davoodi M. J., Houshyar E. 2009. Energy consumption of canola and sunflower production in Iran. American-Eurasian Journal of Agricultural \& Environmental Sciences. Vol. 6. P. 381-384.

16. Tashtoush G., Al-Widyan M. I., Al-Jarrah M. M. 2004. Experimental study on evaluation and optimization of conversion of waste animal fat into biodiesel. Energy Conversion and Management. Vol. 45. P. 2697-2711.

17. Tyson Shaine K. 2001. Biodiesel Handling and Use Guidelines. Report No. NREL/TP-58030004. Golden, CO: National Renewable Energy Laboratory.

18. Vollmann J., Moritz T., Kargl C., et al. 2007. Agronomic evaluation of camelina genotypes selected for seed quality characteristics. Industrial Crops and Products. Vol. 26. No. 3. P. 270-277.

19. Zaleckas E., Makarevičienè V., Sendžikienè E. 2012. Possibilities of using Camelina sativa oil for producing biodiesel fuel. Transport. Vilnius. Vol. 27. No. 1. P. 60-66. 
Violeta Makarevičienè, Eglè Sendžikienè

LIFE CYCLE PARAMETERS AND BIOLOGICAL DEGRADATION OF BIODIESEL FUEL PRODUCED BY USED CAMELINA SATIVA OIL

\section{Sum mary}

Aiming to decrease the negative impact of biodiesel fuel production on the food sector it is necessary to use the resources of oil products or waste materials. Mixtures of fatty acid methyl esters of Camelina sativa oil and waste fat in proportion of $1: 1$ meet the quality requirements for biodiesel fuel. It was determined that the value of the life cycle energy efficiency indicator $\left(R_{1}\right)$ of this fuel is directly proportional to the Camelina sativa productivity. Energy demand for the production of Camelina sativa oil methyl esters (JME) is higher than energy accumulated in JME (value of energy efficiency indicator is lower than 1), therefore when productivity of Camelina sativa seeds is equal and lower than $1.6 \mathrm{t} / \mathrm{ha}^{-1}$, JME could not be referred as renewable fuel. The values of the energy efficiency indicator for fatty acid methyl esters produced from waste animal fat are higher comparing with that of JME. For animal waste methyl esters (AME) the value of $\mathrm{R}_{1}$ is 4.94 . For twocomponent fuel mixture (JME-AME in proportion of $1: 1$ ) the value of the energy efficiency indicator in case of $1.28 \mathrm{t} /$ $\mathrm{ha}^{-1}$ productivity of Camelina sativa seeds equals to 1.34 , when productivity is $1.6 \mathrm{t} / \mathrm{ha}^{-1}, \mathrm{R}_{1}$ is 1.5 . It was found that mixtures of Camelina sativa oil and waste fat methyl esters (in proportion of $1: 1$ ) meet the requirements of biological degradation for biofuel: more than $90 \%$ of this mixture biologically degraded in 21 days.

Key words: fatty acid methyl esters, life cycle, efficiency indicator, biological degradation 